\title{
Strengthening the bond with our American colleagues
}

D espite its small population, or perhaps because of it, Canada has produced a large number of dedicated, creative and energetic plastic surgeons who have been leaders in craniofacial, microvascular, transplantation, hand, nerve and aesthetic surgery. They have earned worldwide reputations as researchers, teachers and clinicians.

Some have continued to broaden their experience in Canada, while others have exported their expertise to other lands, most notably to our southern neighbour, the United States, where many have become outstanding professors and department heads.

There has always been a common bond with our American cousins. We have joined and contributed to each other's organizations and associations.

Dr E Fulton Risdon of Toronto, Ontario, founding member and first President of the Canadian Society of Plastic Surgeons, was also a founding member and the third President of the American Association of Plastic Surgeons and a founding member of the American Board of Plastic Surgery. Dr Bruce Williams of Montreal, Quebec is a Past-President of both the Canadian Society of Plastic Surgeons and the American Society of Plastic Surgeons.
Dr Bruce Connell of California is a PastPresident of the Canadian Society for Aesthetic (Cosmetic) Plastic Surgery. The American Society of Plastic Surgeons has held its annual meeting in Canada on numerous occasions. The editorial board of The Canadian Journal of Plastic Surgery is made up of outstanding colleagues from coast

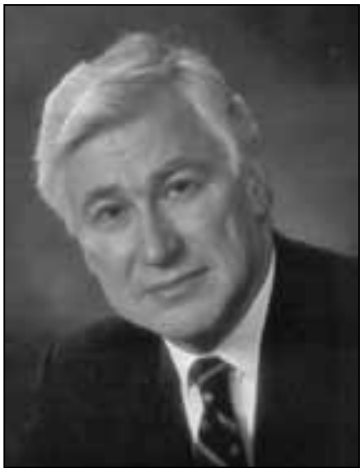

Peter E Wyshynski to coast in both countries.

To further this bond, the board of The Canadian Journal of Plastic Surgery unanimously voted to distribute the journal to our American colleagues as both a courtesy and a forum to discuss new ideas and new problems in our specialty of plastic and reconstructive surgery.

I hope it will be well received.

Peter E Wyshynski MD FRCSC Editor-in-Chief 